\title{
THE PRESENTATION OF SELF IN EVERYDAY ETHER: A CORPUS ANALYSIS OF STUDENT SELF-TELLINGS IN ONLINE GRADUATE COURSES
}

\author{
Carla Meskill, Gulnara Sadykova \\ University at Albany, State University of New York
}

\begin{abstract}
This study examines the patterns and substance of student self introductions in nine fully online graduate courses in education. A composite of social identity frameworks with an emphasis on language as the tool for self-presentation is first developed to guide the analysis and interpretation of these data. In particular Sfard and Prusack's operationalization of the telling of identity [1], along with Bruner's construct of turning points in self-tellings [2] are discussed and employed as analytic lenses. The question of how, in a tightly defined social/academic context, adults use written language to present themselves to others is taken up through content analysis supported by linguistic concordancing. Two hundred twenty-three "Meet Your Classmates" entries are examined for their form and content. Entries composed by preservice teachers, inservice teachers, and doctoral students reveal differences regarding academic and professional identity-telling with the tenacity of institutionally situating and situated forces prevailing.
\end{abstract}

\section{KEYWORDS}

Social Identity, Online Identity, Language of Introductions, Asynchronous Courses, Education, Preservice Teachers, Inservice Teachers, Concordancing

\section{INTRODUCTION}

What do we know about students in our online distance education courses? What do they choose to tell us about themselves? What mechanisms do they use to present this information? When asked for a self introduction in an asynchronous online course, what autobiographical stories do students tell? In attempting to address these questions, theoretical principles from four broad areas are employed: language in education, critical discourse analysis, narrative identity, and computer-mediated communication. Using these multiple points of entry, we examined the text archives of the Meet Your Classmates (MYC) entries of 223 graduate students in educational theory and practice in an attempt to characterize patterns of selfpresentation. We used simple concordancing software to establish patterns in the corpus of student entries. Patterns of self-tellings were examined by states as defined by Sfard and Prusak [1], and what Bruner [2] terms the "turning points" that are characteristic of self-tellings. These two analytic tools were used to compare the forms and substance of self-introductions by students' academic status: preservice teacher, inservice teacher, and doctoral student.

We first lay out a brief overview of current social identity terrain as discussed within related fields and how these concepts might apply in analyses of self-introductions. The analytic lenses of self-tellings as applied to our examination of student online self-introductions are also discussed. How identity in computer-mediated communication has been conceived and examined socioculturally is then considered. 
Finally, we present the findings of our analyses and discuss their implications for online instruction and for instruction broadly conceived.

\section{SOCIAL IDENTITY}

I think of Self as a text about how one is situated with respect to others and toward the world - a canonical text about powers and skills and dispositions that change as one's situation changes from young to old, from one kind of setting to another.

Jerome Bruner [3]

In recent decades, a widely accepted working construct of identity has proved illusive [4]. Although a uniform sense of the term seems a common component of popular lay speech and popular culture whereby it typically refers to personal information that can be stolen and misused, within and across the realms of academe its sense shifts between disciplines and ideologies. From the broad and tenuous "way of being in the world" [5, p.151], to the more focused "how people understand their relationship to the world, how that relationship is constructed across time and space, and how people understand their possibilities for the future” [6, p.410], the term is widely used across fields, across discourses, and for multiple purposes with the most common orientation being towards the players who populate given social contexts. For the purpose of this study, the term social identity is used in a restricted sense as it applies to, and is reflected in a single telling by an individual when introducing him or herself in an online graduate course.

\section{FRAMEWORK}

In his landmark The Presentation of Self in Everyday Life, Irving Goffman [7] engages the notion of social identity and how individuals present themselves through what he calls "impression management" in the varying social contexts of everyday life. Current notions of identity indeed converge around the dynamic nature of the social self in interaction with others; the fact that we all possess a repertoire of social identities that are simultaneously subject to continual change $[8,9,10,11]$, to power relations between speakers $[12,13,14,15]$, and that are inextricably dependent on the contexts in which they are both formed [16] and exercised [17, 18].

To present oneself effectively in various social contexts and to be attended to by others, the actual "telling" of who one is, what Bruner calls "self-telling", must have a solid "why tell” behind it. The "why tell" behind the information one selects to share when introducing oneself to others is steered by numerous factors, including one's personal narrative repertoire at the time of the telling and the context in which the introducing takes place. First and foremost, Bruner argues, "we wish to present ourselves to others (and to ourselves) as typical or characteristic or 'culture confirming' in some way" [2, p.29]. The aim is to present oneself in a manner that is socially and institutionally sanctioned given the context and interlocutors whereby certain shared presuppositions about oneself and one's place in the world can be mutually and unambiguously understood. In other words, telling about ourselves is most often a bid for membership [19].

For Bruner, a key component of self-telling is that of turning points-linguistic means of organizing and marking attention to important life events. Turning points serve to "distinguish what is ordinary and expectable ...from that which is idiosyncratic and quintessentially agentive” [2, p.32]. Turning points are what mark the individual as unique -"quintessentially agentive" - within the conventional frames of self presentation while also anchoring one's identity to the known, to the contextual community. Turning points are chronologically situated by a speaker/writer on an imagined timeline, an underlying space for 
the plotting of events [20, 21]. In this study, the notion of turning points is used to determine patterns as well as to assess similarities and differences in self presentations. Tellers of their life stories use the narrative conventions called for by the community in which they are situated, for which they are bidding membership, and in which they are constructing their tellings. Such narrative turning points not only provide structure, but also the cohesion needed by hearers/readers of the stories to make sense of tellers' lives.

In addition to Bruner's turning points, we employ the analytic device of states using Sfard and Prusak's recent definition [1]. In their effort to operationalize the concept of identity for educational research, Sfard and Prusak cast identity telling and identity making as communicative, discursive activities. The central component to their definition is that identity telling is storytelling and, as such, can be subject to linguistic analysis. To qualify as being identity telling, statements made (stories told) about identity are

- reifying - a statement about a state;

- endorsable - consistent with the world;

- significant — when a change in state will mean a change in perception of reader/listener.

These components of identity telling are not only invaluable analytic tools in the study of identity as presented through language generally, they are also particularly relevant to a study of academic identity, a context in which institutional norms are well established and widely understood. To talk about one's life using statements about states of being (e.g., where one "is" within an academic program and/or a career track) is a natural component of academic discourse communities. These statements are likewise endorsable in that they make reference to academic degrees and employment experience that are, in theory, verifiable. Academe is especially predisposed to states through its system of grades, degrees, certifications, and promotional structures, all of which are reifying and endorsable. Moreover, academe to a large degree determines legitimacy in the broader socioeconomic realm by providing "endorsements"; degrees, diplomas, and status.

The third requirement for Sfard and Prusak's identity telling is that the utterance be significant. To be significant it must change the interlocutor's understanding of the teller's identity. This element of significance aligns with Bruner's why tell? component of self-telling. When talking of oneself, statements must make a difference to the interlocutor's perception of the person presenting. In order to be significant and to answer Bruner's why tell?, one must have a good sense of who one's listeners/readers are and what the community/contextual norms might be to make a successful bid for membership. Given this knowledge, the storyteller/autobiographer can then consider and construct herself the way she understands how she ought to be in a given context.

As the focus of this study is the form and content of self introductions in fully asynchronous online graduate courses, one would suspect that the anatomy of the social and institutional motives behind such written presentations of self are indeed dependent on the context, power relations, and, most importantly, the writer's understanding of his or her relationship to this text-only microworld. Moreover, the shared cultural model of class introductions might assure that certain known conventions are followed [22]. As such, a manifestation of students' understanding of academic online culture and their place within it gets expressed in written language when they are directed to share with other students and their instructors who they are. 


\section{IDENTITY ONLINE}

The popular notion that technologies can somehow influence and even dictate human behavior has long persisted. However, in the last decade, this technocentric perception has seen its demise among social, cultural, and even economic theorists. To a great extent, Sherry Turkle's work on online fantasy identities [23] marked the obsolescence of technocentric, cause and effect understandings of human-machine relationships and paved the way for new modes of sociocultural investigations of evolving online communities and the social identities that develop within these. Her groundbreaking Second Self illuminated the question of who we are and how we present ourselves in online environments. Her work has drawn the attention of cultural theorists, anthropologists, and sociologists among others and has underscored the importance of telling the complete stories of individuals interacting online. Numerous studies that examine the social dimensions of Computer Mediated Communication (CMC) discourse, and that employ ethnographic, anthropological, and discourse analytic techniques have subsequently appeared in the last decade [cf., 17, 24, 25, 26, 27, 28].

Issues around online identity and its authenticity have abounded in the popular media where news of identity theft and other online scams, whereby imposters take advantage of the internet's visual anonymity to steal, are common. Contrary to this version of human behavior on the internet, the vast majority of people who communicate on the web do not breach the trust of others by misrepresenting who they are $[18,29]$. Indeed, there are some online social spaces where writers experience less inhibition and more openly express their true nature than in face-to-face (f2f) contexts [30]. In the limited number of extensive studies of internet communication, the aspect of community membership-exhibiting those discursive patterns and strategies the writer deems as fitting the conventions of a given online contexthave emerged as predominant. Bidding for membership online-like Goffman's f2f impression management-is a primary social response that requires that certain situational assessments be made and the performance of identity undertaken accordingly. In an online community, this takes place chiefly through written language.

It is widely held that the online social spaces that have organically evolved through our shaping of technologies to our own human needs and purposes are sites where specific discourse conventions and self presentation practices have likewise evolved. That is, like live human-human interaction, how identity gets performed is very much context-dependent. One fairly uniform assumption is that online communication hovers somewhere between text and speaking with most CMC communicators claiming that what they write online is more like speaking than formal writing [31]. As in f2f communication, what we say with text in CMC often conveys messages about our background, our educational level, and our orientation towards the topic and context. Our self-presentation is imbued with bids for membership in the groups in which we communicate: newsgroups, lists, blog feedback, chats, and the like. Even in the construction of personal webpages there are evolving in-group, out-group conventions, what Hine calls "authenticity claims", that are closely adhered to [25] with the means by which membership requirements are determined and bid for being chiefly through written language.

Languaging identity online takes on special significance as new social spaces are continually evolving and as we are ever-adapting our discursive practices to these novel venues. The difference between these constant adaptations and those we make in real life is that it is the text, the words on the screen that do the talking, modulating, gesticulating, etc. In arguing for the centrality of language in both constructing and interpreting social identity, Ochs characterizes the two-way, synergistic nature of language and social identity as follows: "[l]inguistic constructions at all levels of grammar and discourse are crucial indicators of social identity for members as they regularly interact with one another; complementarily, social identity is a crucial dimension of the social meaning of particular linguistic constructions” [10, p.288]. 
Ochs goes on to emphasize the individual agency behind these verbal constructions of self with and through language: "In all situations, even the most institutionalized and ritualized, people are agents in the production of their own and others' social selves” [10, p.296] [emphasis in the original]. In the study of online self-presentations, we have the luxury of studying the agentive self-tellings of students' social and academic selves as reflected through their linguistic choices, choices that, like in f2f communication, are constrained by shared and unshared understandings, communicative goals (individual and collective), and personal accountability. Like Goffman's f2f impression management, we are often called on to do the same via written language online.

\section{METHODOLOGY}

\section{A. Setting}

The setting for this study is comprised of nine graduate courses in Education: two courses in Educational Research, three courses in Media Literacy and four courses in Using Media in the Language Classroom. All courses were delivered asynchronously online. All nine courses treat educational theory and practice. Students are pre- and inservice educators and doctoral students interested in teaching and learning with technology. To successfully complete these courses, they are directed to logon at least five times per week and engage in readings, discussions, group work, and to complete written assignments. Only in rare instances do students and their instructors speak to or see one another face-to-face: all communication is mediated through a learning management system interface. Assignments, evaluations, and discussions are orchestrated in a widely used, easily navigable, course management system.

\section{B. The Meet Your Classmates Entries}

The first task for students to undertake in these online courses is to go to the Meet Your Classmates (MYC) section of the course and post a self- introduction. These mini-autobiographies can be accessed by the instructor and by other students in the course to read and reference at any time during the semester. For example, some students and instructors report opening an individual's MYC entry in one window while reading that person's discussion post or class assignment in another. In this way they report having a better sense of the author of the text they are reading.

Students are provided the following instructions for the MYC entry task:

\section{Tell your classmates/students a little about yourself.}

Fields for composing text, attaching photographs, and linking to websites are provided. Once they have submitted their MYC entry, students are instructed to proceed into the course.

The MYC entries were archived from nine graduate courses conducted over a two-year period. Students in these courses all shared the common goal of achieving a graduate degree in education and securing, or continuing related professional work in their academic area. They are all, in short, in the process of building their professional identities through advancement in higher education. It was of interest, therefore, to compare the ways this was accomplished by students at three different academic/professional career points: preservice teachers (novice, non-practicing), inservice (experienced, practicing), and doctoral students. For all participants the question of what constitutes perceived membership - as expressed through one's states, narrative turning points, and progress in the academic context - is of interest as well as if and how this differs between the three groups. Because the number of doctoral students was so small ( $n=9)$, and because their entries were markedly different in form and content, 
comparison of their entries with those of the other two groups (preservice=95; inservice=127) is greatly restricted. For this reason, discussion of the doctoral student entries will be taken up separately.

\section{Research Questions}

The following questions guided data collection and analyses:

1. How do graduate students present themselves in their brief, online self introductions?

2. What are the formal elements (structure and content) of these online self introductions?

3. Do the structure and content of these autobiographies differ when composed by preservice teachers, established inservice professionals, and doctoral students?

4. What makes these written representations of self unique to the context for which and in which they are composed?

5. How might linguistic concordancing serve to support our understanding of online social, professional, and academic identity?

The corpus of MYC entries was converted into .txt files and the Simple Concordance Program (http://www.textworld.com) used to capture patterns of states and turning points as these fell out similarly and differently between the three groups of students. According to Biber et al. [32], corpus-based concordancing allows the following:

- representation of naturally occurring discourse from a range of registers;

- (semi) automatic linguistic processing that assists in determining the linguistic characteristics of single or multiple texts;

- accurate quantitative analysis of linguistic features;

- possibilities to apply both corpora and analytic method to subsequent studies.

Concordances of the MYC entries were run on a range of lexical and syntactic items to capitalize on these features and treat the MYC entries and the students' self tellings expressed in them as discursive. Additionally, the concordanced data were handcoded by the following:

- $\quad$ state, academic

- state, professional

- state of mind

- action (turning point), academic

- action (turning point), professional

- other (personal, geographic, etc.)

\section{MYC Models}

By happenstance, for six of the courses from which these data were drawn instructors initially supplied a MYC entry of their own. In the three other courses instructors did not do so. The difference in number of words per MYC entry between those who had an instructor model for the entry and those who did not is worth noting (Table 1, below). Although there is limited empirical evidence of online communicators using uptake in their postings, indeed there is some evidence that they do not [33]. In the case where the source of the model is in a position of authority (the instructor for the course), it appears to make a difference in the length of students' self-tellings. In addition to responding to the authoritative text of the instructor, by assessing the length and content of instructors' postings students may also be gauging an 
appropriate format/length for their bid for membership in the group, an aspect reflected in the overall content of their entries as we shall see.

\begin{tabular}{|l|l|l|l|}
\hline & With Model & Without Model & All \\
\hline Preservice (rF38+57) & 88 & 63 & 73 \\
Irservice (rF94+ 33) & 110 & 82 & 103 \\
Doctoral( $\mathrm{rF9}$ ) & 155 & - & 155 \\
\hline
\end{tabular}

Table 1. Average Number of Words per MYC Entry

\section{RESULTS}

\section{A. Overall MYC Content}

To some extent introducing oneself in a class can be viewed as ritualized. Though what gets said and how may vary from discipline community to discipline community, the basic script appears to remain somewhat stable. In these entries, we can indeed glimpse some consistency in presenting or "performing" oneself [7] within the highly codified institution of education: one states who one is in relation to the institution and oftentimes who one is outside of the institution whereby a link between the two is significant and endorsable.

The content of the MYC entries appears to have been developed through a sense of who writers saw themselves as, individually and collectively, in their degree programs and, by extension, to others in the same or similar academic programs: practicing teachers relate themselves as teachers, preservice teachers as preservice teachers, students as students. These are the pivotal points of identity that appear to be collectively reifying through the MYC entry. All writers appear to be intimately familiar with the codes and context of this classroom-based genre of communication. All self-identify either via their academic status and/or as professionals of some kind. All state their progress in achieving the next level on the academic/professional membership trajectory. 


\begin{tabular}{|l|ccc|ccc|}
\hline & \multicolumn{3}{|c|}{ INS ERVICE } & \multicolumn{3}{c|}{ PRESERVICE } \\
\hline & Total & Model & No model & Total & Model & No model \\
& $\mathrm{N}=12,898$ & $\mathrm{~N}=10,228$ & $\mathrm{~N}=2,670$ & $\mathrm{~N}=6,854$ & $\mathrm{~N}=3,297$ & $\mathrm{~N}=3,557$ \\
\hline Teach & $18.8(243)$ & $17.5(179)$ & $23.9(64)$ & $12(82)$ & $10.6(35)$ & $7.0(25)$ \\
School & $113(146)$ & $11.1(114)$ & $12.7(34)$ & $4.2(29)$ & $3.6(12)$ & $5.3(19)$ \\
Year & $9.9(125)$ & $8.9(91)$ & $13.1(35)$ & $7(48)$ & $6.4(21)$ & $8.4(30)$ \\
Class & $8.5(110)$ & $8.5(87)$ & $8.6(23)$ & $6.9(47)$ & $7.9(25)$ & $5.9(21)$ \\
Work & $8.4(108)$ & $9.0(92)$ & $6.4(17)$ & $8.5(58)$ & $6.7(22)$ & $11.0(39)$ \\
Look forward & $6.4(82)$ & $6.6(68)$ & $5.2(14)$ & $3.2(22)$ & $3.9(13)$ & $2.5(9)$ \\
Course & $5.7(74)$ & $5.9(60)$ & $5.2(14)$ & $5.3(36)$ & $5.2(17)$ & $5.6(20)$ \\
Program & $49(63)$ & $4.9(50)$ & $5.2(14)$ & $8.3(57)$ & $7.6(25)$ & $9.3(33)$ \\
Or-line & $49(63)$ & $4.9(50)$ & $4.9(13)$ & $6.1(42)$ & $7.0(23)$ & $5.3(19)$ \\
Studert & $4.8(62)$ & $4.7(48)$ & $5.2(14)$ & $5.5(38)$ & $5.2(17)$ & $5.9(21)$ \\
Educate & $43(56)$ & $4.5(40)$ & $6.7(18)$ & $4.1(28)$ & $3.3(11)$ & $4.5(16)$ \\
Sermestex & $4.4(55)$ & $4 . \Upsilon 48)$ & $2.2(6)$ & $4.8(33)$ & $4.9(16)$ & $4.5(16)$ \\
Grade & $43(55)$ & $4.5(40)$ & $6.7(18)$ & $0.9(6)$ & $09(3)$ & $0.8(3)$ \\
Leam & $36(47)$ & $3.7(38)$ & $3.4(9)$ & $2.6(18)$ & $4.2(14)$ & $(4)$ \\
Degree & $3.6(46)$ & $3.6(37)$ & $3.4(9)$ & $4.4(30)$ & $5.2(17)$ & $(13)$ \\
\hline
\end{tabular}

Table 2. 15 Most Frequently Used Roots (Frequency per 1000 Words, Raw Number in Brackets)

Table 2 presents by inservice descending order the fifteen most frequently occurring words by root in the MYC entries. As is reflected in these frequencies, inservice teachers highlight where they teach, what they teach and how long they have taught. Preservice teachers relate where they completed their undergraduate studies, what they studied, and where they plan to go academically and professionally. These trends are well reflected in the most commonly occurring lexical items. The conclusion that can be drawn from this list is that student entries reflect bids for membership to the group, the characteristics of which they see as converging around educational goals and professional prospects. By locating themselves institutionally, both academic and professional, writers literally enter a bid for membership in the community that they are in the process of establishing. 


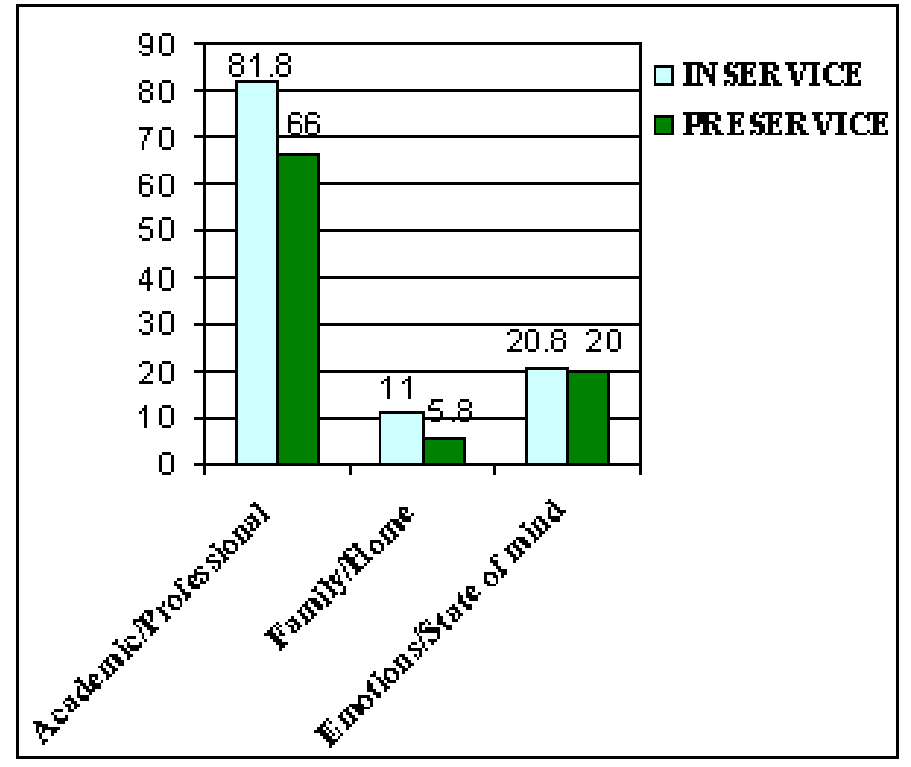

Table 3. Most Common Topics by Group

In their effort to establish common ground and locate themselves accordingly, writers focus primarily on academic and professional status. As in Davis and Mason's [34] study of online communication where "participants chose to derive or construct authority externally from professional credentials" [34, p.55], these graduate students, albeit to varying degrees, presented themselves primarily in terms of their academic and professional status and accomplishments. This is reflected in Tables 2 and 3 (above). Also, common content to both groups were expressions of looking forward to the course and to working with others, and mention of marital status, children, and pets. Both groups also frequently identified themselves by the number of courses they had completed or had yet to complete in their particular graduate program.

Structurally, these texts more clearly resemble a spoken versus a formal written style of communicationexactly what one would expect from CMC communications. Indeed, writers appear to draw their readers' attention to the content of their entries, not to the form and structure they employ. They tend to thus employ anti-rhetorical devices such as simple declarative sentences with few rhetorical transitions [35]. Unlike spoken f2f classroom self-introductions, however, the MYC entries do not generally begin with My name is statements. This would be redundant information as the entry is otherwise automatically labeled with the writer's name in two highly visible places on the screen. Alternatively, most entries begin with a greeting: Hi! Greetings! and the like. If not, the writer launches directly into self description (I am a... I teach... I currently... and the like); statements about states as related to their academic professional status. A typical overall format of the entries can be best described as casual listing of these states along with chronologically ordered academic and professional turning points. These appear in paragraph format, but not as constructed, cohesive written paragraphs. The casual nature of the entries is also marked by a predominantly verbal rather than nominal style. Like spoken, casual texts, the MYC entries are also "characterized by relatively high frequencies of the present tense, by relatively many verbs like think and feel, which express private states and emotions” [36, p.137], characteristics that align with Biber et al.'s research on spoken language corpora [32].

Although the corpus of MYC entries was concordanced using several potential linguistic indicators of state, by far the most productive indicator was the verb be (see Table 4, below). For identity telling, "the use of is-sentences...do the job of 'freezing the picture' and turning properties of actions into properties 
of actors, [and] is grounded in the experience - engendered expectation - indeed, hope - that despite the process of change, much of what we see now will repeat itself in a similar situation tomorrow” [1, p.16]. $B e$ statements and other statements that reveal academic, professional and states of mind were handcoded as follows:

- state, academic

- state, professional

- $\quad$ state of mind

As indicated in Table 4, as might be expected, the preservice teachers' statements more frequently described their academic states or status - “I am a ...student”-while the inservice teachers' statements more frequently described their professional states or status - "I am a teacher ..." While both groups made statements about their state of mind - "I am nervous..." "I am looking forward to...", the preservice teachers were more inclined to express these states than their senior counterparts.

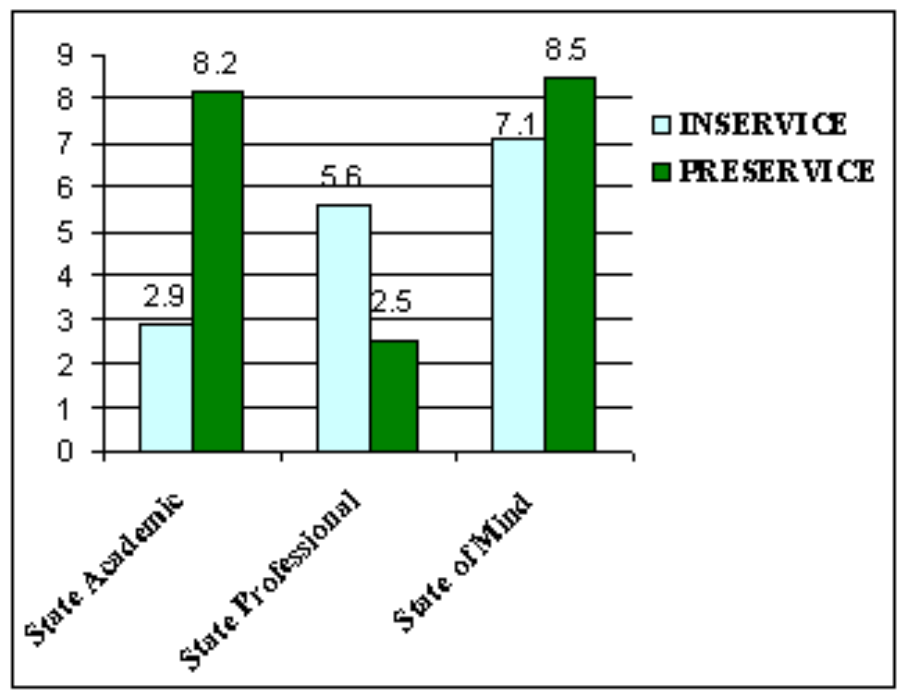

Table 4. States-Academic, Professional, of Mind-by Group

\section{B. Turning Points}

Turning points were handed coded as either academic or professional. For past actions, Table 5 illustrates again that the most frequently employed verbs in the past tense were those denoting academic and professional acts. 


\begin{tabular}{|l|cc|}
\hline & $\begin{array}{c}\text { INSERVICE } \\
\text { (total words }=12,898)\end{array}$ & $\begin{array}{c}\text { PRESERVICE } \\
\text { (total wor ds }=6,854)\end{array}$ \\
\hline Taught & $1.5(19)$ & $0.44(3)$ \\
Graduated & $0.9(12)$ & $3.4(23)$ \\
Was & $0.7(9)$ & $0.3(2)$ \\
Worked & $0.5(7)$ & $0.44(3)$ \\
Studied & $0.16(2)$ & $0.15(1)$ \\
Learned & $0.08(1)$ & $0.15(1)$ \\
Completed & 0 & $1.2(8)$ \\
Finished & 0 & $0.7(5)$ \\
\hline TOTAL & $3.9(50)$ & $6.7(46)$ \\
\hline
\end{tabular}

Table 5. Most Frequently Used Verbs Describing Past Actions (per 1000 Words, Raw Number in Brackets)

Table 6 (below) illustrates the high frequency of reference to academic turning points for the preservice group and the contrasting high frequency of professional turning points for inservice teachers. Turning points that are most pertinent to preservice teachers are clearly tied to their academic lives while the turning points for inservice teachers are both more frequent by virtue of their having had relatively more life experience in general, and lengthier professional experience as teachers in particular.

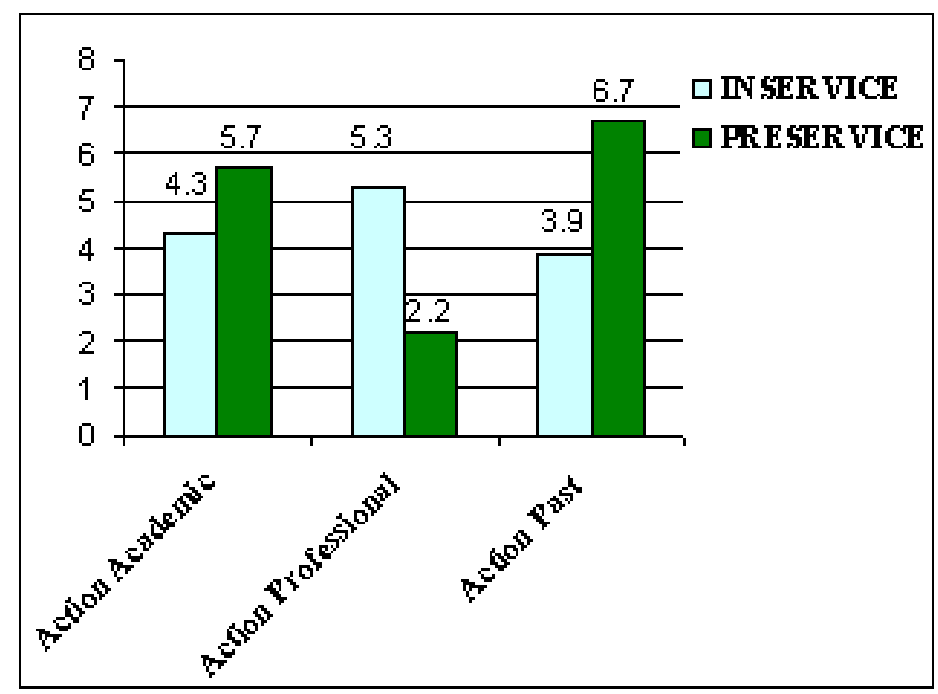

Table 6. Frequencies of Turning Points by Group

Comparisons by the linguistic patterns expressing states along with those that report turning points reveal informative distinctions between the two groups. First, these differences indicate shared understanding of an underlying institutional trajectory, what Gee, Allen and Clinton [37] call "achievement space”, used by students when selecting the information to include in these brief autobiographies with their own positions along the trajectory serving as the main chronological anchor in their identity tellings. Secondly, these students generally mark their status on an imaginary timeline made up of time remaining until a degree is obtained, time in profession, marital status, and the like. Finally, they state an endpoint at which they 
envision themselves being at the end of the academic/professional trajectory.

\section{Awareness of Audience and 'Achievement Spaces'}

According to Ochs [10], the choices that a speaker makes are continually mediated by their and their audience's understandings of the context and the conventions of the moment. In this online context, audience includes the instructor from whom a nod confirming that she recognizes the student as a serious one is sought. Other students in the course are most likely strangers to the writer, the only information the writer having about the group being through others' MYC entries. Statements made in the MYCs, then, draw strategically on what the writer can confidently assume is shared knowledge given the non-present group and the context of their tellings. The substance and structure of these entries evolve accordingly, the designated identity serving as the lynchpin between the socially constructed and the individual experiences reported. Identity trajectories [5, p.163], whereby the future is laid out as part of one's past and present, are particularly salient here. The common underlying assumption is that what matters in an academic (albeit online) context and the social/academic terrain is well understood: it is successful progress along this trajectory to a final state of academic and professional development. These individuals have spent a great portion of their waking lives immersed in the academic culture. Its structures are consequently well, if not unconsciously, appropriated. A major imperative of these self-tellers is to place themselves as members; a key strategy for doing so being to place oneself along a trajectory of academic accomplishment. The underlying trajectory along which each student situates himself or herself is an act of "self-location...through autobiography we locate ourselves in the symbolic world of culture" [20, p.133].

Locating selves culturally within the structures of educational institutions is a symbolic placing along well-known metaphorical pathways to achieving the endorsements of those institutions. This act of locating very much resembles the use of “achievement spaces” in Gee, Allen and Clinton's findings regarding middle and upper middle class adolescents as they told about themselves [37]. A similar use of self-placement along an achievement trajectory is evident. Intermixing statements about one's personal life is a secondary strategy of locating oneself in society in a way that reinforces membership. Part of group membership is understanding what is important for your interlocutors to know about you in order to 1) interpret your utterances and 2) grant you membership. In the main, these online students do not stray from the member trajectory in their self-tellings. There are occasional bids for individuality and creativity, but only once the base membership trajectory information has been supplied. They are thus illustrating unequivocally what Wortham terms "versions of social-historical categories [that] are contextualized and circulate locally” [11, p.717].

\section{Straying From the Script-The Doctoral Students}

The few doctoral student entries $(n=9)$ interestingly broke with this pattern. Although there are too few doctoral student entries to make any numerical comparisons with the pre and inservice teacher/students, the length of their entries is strikingly longer (see Table 1) and tend to be characterized by the cohesion of written, not spoken forms. There is also a uniform lack of trajectory/achievement placement in favor of the personal/professional commentary of advanced scholars in training. Doctoral student entries tend to be less about professional membership and more idiosyncratically personal: statements of research interests that are interspersed with personal sentiments and, in some cases, detailed life stories. This may reflect this group's socialization to the academy beyond achieving the teaching credentials the others seek. Indeed, a distinctive characteristic of academe is its "complex public-private dialectic" [38, p.144], an aspect of the academy that might explain the doctoral students' comfort with sharing the personal as it relates to who they are as scholars. This marked difference in the types of states and turning points reported and the manner in which they are presented represents a different type of membership bid; such 
bids of necessity aligning with local understandings and expectations concerning what it is to be a student/graduate student in an instructor-monitored academic context.

\section{IMPLICATIONS}

As the number of online courses grows larger, more than ever we need mechanisms for understanding who our students are-at least who they are presenting themselves as being at the time they are taking our classes. Instructors may, as a matter of course, take informal tallies of their students' positions within the academy/profession, but supporting this impressionistic process with hard, easily sorted data may be helpful in ascertaining more precise views of who students see themselves as being in an online course through the self-telling choices they make. Better understandings of who our students are through analysis of their ways of telling their own stories might consequently assist in shaping instructional conversations in online courses. Attention to individual and collective learner identity may also help promote learnercentered pedagogical approaches in asynchronous teaching and learning environments. Moreover, increased awareness of the forms online learner identity can take may also help attenuate the sometimes constraining forces of institutional normalizing that get imposed on self expression. That is, the more aware instructors are of institutionally generated scripts of student identity, the better equipped they may be to counteract mimicry, marginalization, and attrition through dialoging with individual learners and thus drawing them out as more than merely institutionally identifiable.

Awareness of the tensions students experience between their more global, as opposed to the decidedly more local identities is an important awareness. As one young preservice teacher lamented, "I never know what college wants you to say". That learners are constructing profiles of themselves that conform to notions of academe is important background knowledge to hold as one designs and implements instructional tasks and orchestrates instructional conversations online. After all, in online environments we don't have the luxury of witnessing our students' immediate reactions to what we present and challenge them with. The study of such self-tellings may be one of many compensatory strategies.

Research on the expression of identity through language has variously examined themes, narrative structures, patterns, code-switching, stylistics, and the rules of genre. Genres are especially powerful determining patterns in the production of self expression as they supply the walls and boundaries that include or exclude elements of culture, ideology, and value. We are thereby "bound by strong conventions regarding not only what we say when we tell about ourselves, but how we say it, to whom, and so on" [20, p.129]. Unstated rules and conventions regarding the presentation of self to others in introductory contexts, then, represent a fairly restricted genre of language use. Add the fact that the context is academe, and the restrictions are even tighter as to what is considered appropriate information to share about oneself. Indeed, a MYC genre appears to be arising out of these very specific human discourse practices: those of academe; those that are a part of a standard, Western sense of felicitous self introduction; and, especially, those that organize along a trajectory of academic/professional achievement. Moreover, because the MYC genre is restricted to the written, to a specific audience, for a restricted purpose, it is unique in the limited number of environmental factors that come to bear in contrast to less institutional, less controlled contexts where self-introductions take place.

In everyday life, our primary tool for informing others about ourselves is language. Stripped of the nonverbal (visual, auditory, and kinesthetic) information available in face-to-face self-introductions, along with the breadth of possibilities for distributed communication, the role of language in its hybrid written/spoken CMC form takes on special importance, especially in how we present ourselves to others and the sense they make of our self presentations online. In the context of asynchronous online selfintroductions, Sfard and Prusak's argument about identity as discursive and thus analyzable from a 
linguistic perspective becomes particularly compelling. If online writers employ utterances that communicate reifying, endorsable, and significant states, these can in turn be readily and reliably analyzed and contextualized patterns determined.

\section{CONCLUSION}

In 1995, Turkle observed that online identity was more "multiple and fluid" than in prior, pre-internet times, and that we were therefore freed to organize and switch our identities at will in the ether [23]. In contrast, this study underscores the power and tenacity of social and institutional influences over how we present ourselves in particular contexts. Where online environments continue to provide unique venues in which to observe free form experimentation in human thought and behavior, certain constraints, as in the case of these online graduate courses, are not attenuated by the fact of the medium, by the venue, nor by forms for self expression. Where other CMC venues may invite the creating and shifting of identities, of protean identities, the Meet Your Classmates entry represents a place where specific, socio-institutional parameters appear to be the common frame. The answer to the question Who am I to be in this context? is clearly delineated by one's knowledge and experience with schooling, by Halliday and Hasan's "model in the mind" [39, p.28] in consort with the online learning community that continually reinforces such conformities [5]. In short, the content selected and the language used in these self introduction entries, as in other studies of academic discourse, was clearly shaped by tenacious institutional customs and controls $[9,40]$.

If social identity is taken as inextricably tied into one's orientation to differing groups, this group of online students and their method of introducing themselves to their instructor and classmates reflect this well. In their bid for membership, online students selected to link their personal and professional experiences to the extant frames they assumed were shared by others given the venue. These shared assumptions were comprised of well established, ingrained notions of academic and professional being that had developed through years of schooling enculturation. Whereas early CMC theoreticians predicted an anarchic override of well established hierarchies and social barriers in favor of social liberation, these subjects' self-tellings reveal quite the opposite. Indeed, in accord with Montovani's [41] observation that CMC reinforces social conformity, these data suggest that placing oneself along, and thereby establishing one's identity on a well established achievement trajectory is a uniform trend for the students in this context of online course self introductions. These controlled self-tellings are miniature reflections of the tenacity of Western institutionalism and ritual. They reflect what is important in the minds of these well educated graduate students who have selected a career in Education. Moreover, they reflect the culture, ideology and value that these young people are taking into their classroom practices. The mantra of achievement and its formative, locally crucial role in identity formation is a powerful theme that plays a determining role in the languaging and consequent shaping of identity in this context with far-reaching implications for education professionals and their spheres of influence.

In sum, learning is very much tied to identity [11] and as such is an integral part of our instructional practices, both online and off. Understanding who our students are becomes even more critical online where we do not enjoy, and our impressions are not swayed by, the sociophysical features of human interaction. One manner of attaining some initial understanding of who our students are and how they see group membership in an online course is to undertake this sort of simple language concordancing. By doing so we can assess the frames and trajectories in which and on which our students collectively and individually self-place while confronting the trend that CMC is reinforcing established social/institutional boundaries and barriers. 


\section{REFERENCES}

1. Sfard, A. and A. Prusak. Telling identities: In search of an analytic tool for investigating learning as a culturally shaped activity. Educational Researcher 34(4): 14-22, 2005.

2. Bruner, J. Self-making and world-making. In J. Brockmeier and D. Carbaugh (Eds.), Narrative and Identity: Studies in Autobiography, Self and Culture, 25-37. Amsterdam: John Benjamins, 2001.

3. Bruner, J. Actual Minds, Possible Worlds. Cambridge, MA: Harvard University Press, 1986.

4. Abdelal, R., Y. Herrera, A. Johnston and R. McDermott. Identity as a Variable. Weatherhead Initiative, Harvard University, 2005. http://www.wcfia.harvard.edu/misc/initiative/identity /publications/ID011605.pdf.

5. Wenger, E. Communities of Practice: Learning, Meaning and Identity. New York: Cambridge University Press, 1998.

6. Norton, B. Language, identity, and the ownership of English. TESOL Quarterly 31(3): 409-429, 1997.

7. Goffman, E. The Presentation of Self in Everyday Life. New York: Doubleday, 1959.

8. Hansen, J. and J. Liu. Social identity and language: Theoretical and methodological issues. TESOL Quarterly 31(3): 567-576, 1997.

9. Kramsch, C. Social discursive constructions of self in L2 learning. In J. Lantolf (Ed.), Sociocultural Theory and Second Language Learning. New York: Oxford University Press, 2000.

10. Ochs, E. Constructing social identity: A language socialization perspective. Journal of Research on Language and Social Interaction 26: 287-306, 1993.

11. Wortham, S. The interdependence of social identification and learning. American Educational Research Journal 41(5): 715-750, 2004.

12. Chen, C. The development of e-mail literacy: From writing to peers to writing to authority figures. Language Learning Technology 10(2): 35-55, 2006.

13. Gee, J. Identity as an analytic lens for research in education. Review of Research in Education 25: 99-125, 2001.

14. Fairclough, N. Technologisation of discourse. In C. Caldas-Coulthard and M. Coulthard (Eds.), Text and Practices: Readings in Critical Discourse Analysis, 71-83. London: Routledge, 1996.

15. Pierce, B. Social identity, investment, and language learning. TESOL Quarterly 29: 9-31, 1995.

16. Luke, A. The body literate: Discourse and inscription in early literacy training. Linguistics and Education 4: 107-129, 1992.

17. Miller, D. and D. Slater. The Internet: An Ethnographic Approach. New York: Berg, 2000.

18. Wynn, E. and J. Katz. Hyperbole over cyberspace: Self-presentation and social boundaries in internet home pages and discourse. The Information Society 13: 297-327, 1997.

19. Schegloff, C. Notes on a conversational practice: Formulating place. In D. Sudnow (Ed.), Studies in Social Interaction, 75-119. New York: Free Press, 1972.

20. Bruner, J. and S. Weisser. The invention of self: Autobiography and its forms. In D. Olson and N. Torrance (Eds.), Literacy and Orality. 129-148. Cambridge: Cambridge University Press, 1991.

21. Polkinghorne, D. Narrative Knowing and the Human Sciences. Albany, NY: State University of New York Press, 1988.

22. D’Andrade, R. A folk model of the mind. In D. Holland and N. Quinn (Eds.), Cultural Models in Language and Thought, 112-148. Cambridge: Cambridge University Press, 1987.

23. Turkle, S. Life on the Screen: Identity in the Age of the Internet. New York: Simon and Schuster, 1995.

24. De Montes, L., S. Oran and E. Willis. Power, language, and identity: Voices from an online course. Computers and Composition 19(3): 251-271, 2002.

25. Hine, C. Virtual Ethnography. London: Sage Publications, 2000.

26. Lee, J. Exploring the relationship between electronic literacy and heritage language maintenance. Language Learning Technology 10(2): 93-113, 2006. http://lt.msu.edu/vol10num2/lee/default .html. 
27. Nakamura, L. Cybertypes: Race, Ethnicity, and Identity on the Internet. New York: Routledge, 2002.

28. Warschauer, M. Electronic Literacies: Language, Culture, and Power in Online Education. Mahwah, NJ: Lawrence Erlbaum, 1999.

29. Byam, N. The emergence of on-line community. In S. Jones (Ed.), Cybersociety 2.0: Revisiting Computer-Mediated Communication and Community, 35-68. Thousand Oaks, CA: Sage, 1998.

30. Meskill, C. Teaching and Learning in Real Time: Media, Technology and Language Acquisition. Houston, TX: Athelstan, 2002.

31. Giese, M. Self without body: Textual self-representation in an electronic community. First Monday 3(4): 1998. http://www.firstmonday.org/issues/issue3_4/giese/.

32. Biber, D., S. Conrad and R. Reppen. Corpus Linguistics: Investigating Language Structure and Use. New York: Cambridge University Press, 2002.

33. Lazonder, A., P. Wilhelm and S. Ootes. Using sentence openers to foster student interaction in computer-mediated learning environments. Computers and Education 41(3): 291-308, 2003.

34. Davis, B. and P. Mason. Trying on voices: Using questions to establish authority, identity, and recipient design in electronic discourse. In P. Levine and R. Scollon (Eds.), Discourse and Technology: Multimodal Discourse Analysis, 47-58. Washington, DC: Georgetown University Press, 2004.

35. Potter, A. Interactive rhetoric for online learning environments. Internet and Higher Education 7: 183-198, 2004.

36. Johnstone, B. The Linguistic Individual: Self-Expression in Language and Linguistics. New York: Oxford University Press, 1996.

37. Gee, J., A. Allen and K. Clinton. Language, class, and identity: Teenagers fashioning themselves through language. Linguistics and Education 12(2): 175-194, 2001.

38. Chouliaraki, L. and N. Fairclough. Discourse in Late Modernity: Rethinking Critical Discourse Analysis. Edinburgh: Edinburgh University Press, 1999.

39. Halliday, M. and R. Hasan. Language, Context and Text: Aspects of Language in a Social Semiotic Perspective. Oxford: Oxford University Press, 1985.

40. Lemke, J. Metamedia literacy: Transforming meanings and media. In D. Reinking, M. McKenna, L. Labbo and R. Kiffer (Eds.), Handbook of Literacy and Technology: Transformations in a PostTypographic World, 283-302. Mahwah, NJ: Lawrence Erlbaum Publishers, 1998.

41. Mantovani, G. Is computer-mediated communication intrinsically apt to enhance democracy in organizations? Human Relations 47(1): 45-62, 1994.

\section{ABOUT THE AUTHORS}

Carla Meskill is Associate Professor, Department of Educational Theory and Practice, University at Albany, State University of New York. Her research interests are in the design and research of technologies as they support language education, topics on which she has published widely.

Gulnara Sadykova is a doctoral student in the Department of Educational Theory and Practice, University at Albany. She is also a faculty member of the Department of Romance and Germanic Philology, Kazan State University, Russia. She holds an advanced degree in Comparative Linguistics from the same university. Her research interests include technology-assisted language learning, online learning, cross-culture/cross-border distance education 